\title{
Traducción onto-epistémica: literatura, integración nacional y autonomía wayuu en Estercilia Simanca Pushaina y Philip Potdevin
}

\author{
Onto-epistemic Translation: Literature, National Integration, and W ayuu \\ Autonomy in Estercilia Simanca Pushaina and Philip Potdevin
}

\author{
Kevin Guerrieri ${ }^{1}$ iD \\ University of San Diego (Estados Unidos)
}

acceso $\mathcal{\odot}$ abierto

Para citaciones:

Guerrieri, K. (2020). Traducción ontoepistémica: literatura, integración nacional y autonomía wayuu en Estercilia Simanca Pushaina y Philip Potdevin. Visitas al Patio, 14(2), 4-23. DOI: 10.32997/RVP-vol.14num.2-2020-2777

Recibido: 15 de mayo de 2020

Aprobado: 15 de julio de 2020

Editor: Silvia Valero. Universidad de Cartagena-Colombia.

Copyright: (C) 2020. Guerrieri, K. Este es un artículo de acceso abierto, distribuido bajo los términos de la licencia https://creativecommons.org/licenses/by-nc$\underline{\mathrm{sa} / 4.0 /}$ la cual permite el uso sin restricciones, distribución y reproducción en cualquier medio, siempre y cuando el original, el autor $y$ la fuente sean acreditados.

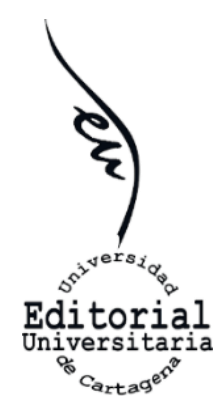

\section{RESUMEN}

Este artículo examina "Manifiesta no saber firmar. Nacido el 31 de diciembre" y otros cuentos de la escritora wayuu Estercilia Simanca Pushaina, y la novela Palabrero del escritor arijuna (no wayuu) Philip Potdevin. El estudio se centra en explorar cómo estos textos literarios abarcan de manera explícita los espacios y las conexiones entre mundos, con un patente compromiso con el pueblo wayuu, y los intersticios entre reconocimiento estatal, integración nacional y autonomía indígena. Se analiza el proyecto estético de cada autor en relación con su búsqueda de la justicia por los wayuu, así como algunas de las tensiones que surgen en la labor de traducción onto-epistémica.

Palabras clave: los wayuu; traducción onto-epistémica; Estercilia Simanca Pushaina; Philip Potdevin.

\begin{abstract}
This article examines "Manifiesta no saber firmar. Nacido el 31 de diciembre" and other short stories by the Wayuu writer Estercilia Simanca Pushaina, and the novel Palabrero by the non-Wayuu writer Philip Potdevin. The study focuses on the exploration of how these literary texts encompass, in an explicit manner, the spaces and connections between worlds, with an evident commitment with the Wayuu people, and the interstices among state recognition, national integration, and indigenous autonomy. Each author's aesthetic project is analyzed in relation to their search for justice for the Wayuu people, in addition to some of the tensions that arise from the work of onto-epistemic translation.
\end{abstract}

Key words: the Wayuu; onto-epistemic translation; Estercilia Simanca Pushaina; Philip Potdevin.

\footnotetext{
${ }^{1}$ Doctor en Literatura en español, Profesor titular del Department of Languages, Cultures and Literatures de la University of San Diego. kevin2@sandiego.edu
} 
La Constitución de 1991 marcó un hito en la historia colombiana respecto al reconocimiento oficial de los derechos de los pueblos indígenas por parte del estado, lo cual sirvió para fomentar la expansión de las expresiones literarias de la nación. En este sentido, "el auge de la literatura wayuu y de otras colectividades indígenas colombianas es inseparable de eventos como la aprobación de la Constitución de 1991 que define a Colombia como una nación compuesta de múltiples etnias, lenguas y culturas cuya conservación y desarrollo es misión del Estado" (Duchesne Winter, 2015: 9-10). Tal como señala Duchesne Winter, fue con el apoyo de la nueva constitución que se declaró el wayuunaiki lengua oficial del Departamento de La Guajira y se activaron muchos esfuerzos de cara tanto a la protección de los derechos como a la promoción de las letras indígenas. Estos fenómenos convergieron con otros acontecimientos clave a nivel internacional a principios de los años 90: se organizaron actos de oposición al quinto centenario del inicio de la colonización europea del continente; en 1992 la activista maya k'iche' Rigoberta Menchú recibió el Premio Nobel de la Paz; al año siguiente la Asamblea General de las Naciones Unidas proclamó el Año Internacional de los Pueblos Indígenas del Mundo (Valle Escalante, 2013). En este contexto hay que mencionar también el levantamiento del Ejército Zapatista de Liberación Nacional en 1994 en defensa de los pueblos indígenas mexicanos y en contra de la globalización neoliberal.

Casi dos décadas después de la nueva constitución de Colombia, se vio la integración de cosmovisiones indígenas y afrodescendientes de manera más profunda en las constituciones de Ecuador y Bolivia, en 2008 y 2009 respectivamente, mediante la noción del "buen vivir" -sumak kawsay (en quechua) y suma qamaña (en aimara). El "buen vivir" proyecta un acercamiento alternativo al desarrollo económico moderno y una filosofía de vida que promueve el biocentrismo en lugar del antropocentrismo y resalta la dignidad humana, la justicia social, la diversidad intercultural y los derechos de la naturaleza (Escobar, 2013). Se puede describir como "un principio fundamental que ayuda a organizar, valorar y significar la experiencia"; con el "buen vivir" o el "vivir bien"—el anaaakuaipa, en wayuunaiki² "se busca la armonía a partir de integrar lo sagrado, lo terrenal y lo material en una concepción de vida" (Pushaina, Villa y Villa, 2016: 248). Sin embargo, en la práctica han surgido contradicciones entre, por un lado, esta producción cosmogónica que plantea una relacionalidad armoniosa con la naturaleza y, por el otro, las políticas implementadas por el estado que acarrean la explotación y mercantilización de recursos naturales según una lógica neoliberal. De hecho, la integración del "buen vivir" en el discurso nacional frecuentemente sirve de justificación retórica para favorecer los mega-proyectos extractivistas al servicio de los flujos del mercado globalizado (Gómez-Barris, 2017: 23-29). En estos conflictos, en los cuales los pueblos indígenas se enfrentan con el estado y empresas multinacionales para defender tierras ancestrales, la política y las negociaciones se trasladan a un espacio de desacuerdos ontológicos (De la Cadena, 2015).

Arturo Escobar (2016) señala que "[a]l resistir el proyecto neoliberal de globalización muchas comunidades indígenas, afrodescendientes, campesinas y urbanas pobres están promoviendo luchas ontológicas [...] por la perseverancia y el potenciamiento del pluriverso en el espíritu del principio zapatista de 'un mundo

2 Estercilia Simanca Pushaina señala que "Anakuaipa" es el nombre de un proyecto de etno-educación que los educadores wayuu han desarrollado para institucionalizar la educación a su manera (Duchesne Winter, 2015: 463). 
donde quepan muchos mundos”' (86). Escobar plantea una pregunta fundamental: "cómo hacer explícita la política onto-epistémica de la traducción que ocurre entre mundos bajo condiciones de conexión parcial que son, al mismo tiempo, relaciones asimétricas" (241). De ahí, surgen más preguntas en el contexto de la literatura: ¿cómo transitan los escritores de textos literarios las conexiones entre mundos, en un papel de traductores onto-epistémicos? ¿Cómo se manifiestan dichos desacuerdos ontológicos en la literatura y cómo se compenetran los textos y los mundos con los cuales se relacionan, más allá de la cuestión de la representación? ¿De qué maneras sirven las tipologías de los estudios literarios para estorbar o bien para facilitar la traducción onto-epistémica? Estas preguntas, así como los sucesos y conflictos que las subyacen, esbozados aquí a grandes rasgos, constituyen el telón de fondo del presente artículo.

En lo que se refiere a la traducción onto-epistémica, un paso inicial consiste en conceptualizar la relación entre mundos diferentes. Marisol de la Cadena plantea el concepto de conexiones parciales, resumido aquí por Escobar (2016): "Proporciona un medio conceptual para entender la complejidad ontológica de los mundos 'realmente existentes', es decir, parcialmente conectados, para entender cómo los mundos pueden compenetrarse y ser radicalmente diferentes al mismo tiempo"; de ahí, la diferencia radical "designa una existencia relacional bajo condiciones de conexión parcial, en las que cada mundo es más que un mundo (no completo ni total por sí mismo) pero menos que muchos (es decir, no se trata de una colección de mundos interactuantes separados); en pocas palabras, todos los mundos están dentro del pluriverso" (241). Al remitirse a la imagen matemática del fractal, De la Cadena señala que "el hecho de que las partes fractales están intra-conectadas, tal como en un caleidoscopio, las relaciones no son externas sino integrales a las partes. Estas no están (ni son) sin aquellas — su relacionalidad inherente impide que se tornen unidades separadas" (2015: 32-33). ${ }^{3}$ Ahora bien, en la traducción entre mundos la noción de controlar la equivocación —usando un concepto propuesto por Eduardo Viveiros de Castro- se refiere al cuestionamiento del proceso mismo de traducción para volver explícitos sus términos onto-epistémicos con el fin de averiguar lo que excede, lo inconmensurable; en otras palabras, se trata de una especie de concientización sobre lo que se ha perdido en la traducción, lo cual puede permitir el surgimiento de entidades múltiples (De la Cadena, 2015: 116).

En este artículo se analizan "Manifiesta no saber firmar. Nacido el 31 de diciembre" y otros cuentos de la escritora wayuu Estercilia Simanca Pushaina, radicada en Riohacha, pero nacida en la comunidad El Paraíso, resguardo Caicemapa en el sur de La Guajira, y la novela Palabrero de Philip Potdevin, escritor arijuna ${ }^{4}$ —no wayuu — oriundo de Cali, Valle del Cauca, y radicado en Bogotá. Lejos de reproducir una limitante oposición binaria basada en concepciones identitarias esencialistas una cosmovisión indígena y otra arijuna - se trata, más bien, de analizar unos textos literarios que abarcan de manera explícita los espacios y las conexiones entre

\footnotetext{
3 "Since fractal parts are intra-connected, like in a kaleidoscope, relationships are not external but integral to the parts. The latter are not without the former - their inherent relationality prevents their "unitization"' (Traducción mía).

4 Duchesne Winter (2015) señala que en wayuunaiki se le dice 'alijuna' o 'arijuna' (la 'r' simple intervocálica es intercambiable por ' $\mathrm{l}$ ') a quien no es wayuu y se restringe a veces a quien no es indígena. La expresión es también muy usada en el español de la Guajira” (458). En los cuentos de Simanca Pushaina aparecen ambas formas ortográficas de la palabra, con "r" y "l".
} 
mundos, con un patente compromiso con el pueblo wayuu, y los intersticios entre reconocimiento estatal, integración nacional y autonomía indígena. En esta reflexión se analizará el proyecto estético de cada autor en relación con su búsqueda de la justicia por los wayuu, así como algunas de las tensiones que surgen en la labor de traducción onto-epistémica.

Las obras más conocidas de Simanca Pushaina incluyen los cuentos "El encierro de la pequeña doncella", finalista en el Concurso Nacional de Cuento Infantil Comfamiliar del Atlántico en 2003, y "Manifiesta no saber firmar. Nacido el 31 de diciembre", que recibió una mención de honor en el Concurso Nacional de Cuento Metropolitano de Barranquilla en 2004. Estos dos cuentos figuran en las antologías El sol babea jugo de piña: antología de las literaturas indígenas del Atlántico, el Pacífico y la Serranía del Perijá, de la Biblioteca básica de los pueblos indígenas de Colombia, publicada por el Ministerio de Cultura (Rocha Vivas, 2010), así como en la compilación Hermosos invisibles que nos protegen: antología wayun (Duchesne Winter, 2015). En 2017 Simanca Pushaina publicó Por los valles de arena dorada, una colección de diez cuentos escritos entre 2002 y 2017, los cuales no siguen un orden cronológico en el libro. En esta colección se crea un mundo ficticio que abarca múltiples mundos interconectados. Muchos de los personajes aparecen en más de un cuento y las historias narradas a lo largo del libro se entrecruzan y se compenetran. El presente análisis se enfoca principalmente en el primer cuento y más adelante se hace referencia a tres relatos más: "Jamü", "Daño emergente, lucro cesante" y "Bultito llorón ¡Cara de indio!".

\section{"Manifiesta no saber firmar"}

"Manifiesta no saber firmar" constituye, sobre todo, una denuncia de las vejaciones, la opresión y la marginación de los wayuu, pueblo indígena que habita la península de La Guajira en Colombia y las inmediaciones del lago de Maracaibo en Venezuela. Coleima Pushaina, la narradora intradiegética, va relatando cómo llegaban a su ranchería los políticos de la ciudad en los tiempos de las elecciones para engatusar a los wayuu con regalos y promesas a fin de conseguir sus votos. Además de las promesas incumplidas, los wayuu también sufrían otras ofensas por parte de los políticos, quienes no respetaban sus costumbres. Cuando llegaban los wayuu a la Registraduría Nacional del Estado Civil a sacar la cédula y así convertirse en parte del electorado oficial, los funcionarios a su vez les aumentaban la edad a los menores, les ponían la misma fecha de nacimiento - el 31 de diciembre- - y les inventaban nombres. De tal manera, se mofaban del analfabetismo de los wayuu y los ponían en ridículo. "Ese día", señala la narradora,

\footnotetext{
me enteré que mí [sic] tío Tanko Pushaina se llamaba Tarzan Cotes, Dorila se llamaba Espina, Shankarit se llamaba Máximo, Jutpunachón se llamaba Priscila, Yaya se llamaba Clara, Castorila se llamaba Cosita Rica, Kawalashiyú se llamaba Marquesa, Anuwachón se llamaba Jhon F. Kennedy, Ashaneish se llamaba Cabeza [...] y por un momento temí que conmigo pasaba lo mismo. (8)
}

Al recibir la cédula de ciudadanía, los wayuu cobraban voz y voto en el cuerpo nacional, pero, simultáneamente, se les injuriaba la dignidad por la desfachatez de los funcionarios y lo que Rocha Vivas denomina el "grafocentrismo burocratizante del Estado" (2019: 230). 
Se inicia el cuento con la llegada de los políticos arijunas, "en unos carros que parecían de cristal": "Aquel mes de octubre, fue como los octubres anteriores que llegaron ellos a nuestra ranchería" (Simanca Pushaina, 2008: 4). La frase citada aparece tres veces en la narración, lo cual sirve para subrayar la repetición del suceso a lo largo de los años. Asimismo, se puede interpretar la descripción de esta escena inicial como una alusión a "aquel octubre" de 1492, cuando llegaron las tres carabelas de Colón a Guanahani, la isla caribeña San Salvador en idioma taíno. En el episodio narrado en el Diario de viaje de Colón, y parodiado a su vez por García Márquez en El otoño del patriarca, los forasteros regalaban bonetes colorados y cuentas de vidrio a los habitantes nativos, pero en "Manifiesta no saber firmar", los obsequios se convierten en café, sacos de maíz, juguetes y cuatro llantas para el tío de la narradora. Conste que el nombre de la ranchería del mundo ficticio es el Paraíso, igual a la de la autora.

El abandono del pueblo wayuu por parte del estado se plasma en el puente caído que no se ha levantado, el molino para sacar agua que aún no ha llegado y la escuela que no se ha construido. La narradora asevera que "[a]hora entiendo porque nunca aprendí a leer y a escribir; ahora entiendo el sentido de las promesas no cumplidas" (Simanca Pushaina, 2008: 4). Dichas promesas también incluyen la que "el señor Candidato" le hizo a Coleima cuando prometió casarse con ella después de darle un beso cerca de la boca. Así se van sobreponiendo los dos planos del conflicto de la historia, todo narrado con un tono conversacional: el plano colectivo e institucional que gira en torno a la perpetua lucha por el reconocimiento del estado y el cumplimiento de sus obligaciones respecto a la ciudadanía, y el plano individual y personal que abarca los sentimientos encontrados — de atracción, desconfianza y desengaño- que tiene la narradora hacia el Candidato. Estos dos planos cobran forma literal y simbólicamente mediante la cédula de ciudadanía y el afiche político del Candidato, pero, de nuevo, hay que recalcar que se trata de una repetición sempiterna de candidatos que dejan de ser "gente buena" al convertirse en Alcalde, Gobernador o bien Senador (7). Es al Candidato de "aquel octubre" al que se dirige Coleima en segunda persona al pensar en su imagen que aún guarda detrás de la puerta. Al final del cuento la narradora afirma que ha logrado mantener su nombre intacto al sacar la cédula, Coleima Pushaina, pero todavía no sabe firmarlo.

Tal como se mencionó anteriormente, este relato está antologizado en varias compilaciones: El sol babea jugo de piña: antología de las literaturas indígenas del Atlántico, el Pacífico y la Serranía del Perijá (Rocha Vivas, 2010), Hermosos invisibles que nos protegen: antología wayuu (Duchesne Winter, 2015) y Por los valles de arena dorada (Simanca Pushaina, 2017). "Manifiesta no saber firmar" constituye una parte del mundo ficticio creado por el artificio narrativo de la autora y compuesto por los diez cuentos de esta última colección. Queremos señalar aquí, sin embargo, una edición ilustrada anterior del cuento en la cual se yuxtaponen explícitamente la obra de ficción con el activismo. Dicha edición (Simanca Pushaina, 2008) consta de 12 páginas de tamaño folio y abarca múltiples componentes. ${ }^{5}$ Hay imágenes de cédulas de individuos wayuu en la portada y en seis páginas más, así como la repetición de una huella digital. La primera página contiene una introducción del escritor wayuu Jesús

\footnotetext{
${ }^{5}$ Rocha Vivas (2019) señala que el cuento se hizo célebre cuando se lanzó en una versión ilustrada en la Feria Internacional del Libro de Bogotá en 2005 (9). Para el presente artículo se usó una edición posterior que no tiene fecha de publicación, pero debe ser de 2008 o después, conforme las fechas incluidas en el texto.
} 
Iguarán que funciona como reconocimiento oficial tanto del mérito literario de la obra como del trabajo de la autora en la lucha por los derechos de la comunidad wayuu. Lo que sigue es una especie de prólogo, titulado "¿Por qué 'Manifiesta no saber firmar?", en el que la narradora relata una historia de su niñez cuando, a los siete años, quería enseñarles a todos los Pushaina a firmar. Empezó con mucho empeño con su abuelo, pero no le salió bien el proyecto y al final este le dijo que "ya estaba muy viejo para hablar con el papel (escribir) y tampoco el papel quería hablar con él (leer)" (3). Esta anécdota sobre la alfabetización se inscribe en un vigente sistema globalizado basado en la colonialidad del poder (Quijano, 2000), y en este caso se resiste a la opresión racializada usando el idioma de los colonizadores. El pequeño acto de resistencia de la niña se transforma con los años en los esfuerzos paralelos de la creación literaria y la acción jurídica.

Justo después del cuento, que ocupa unas ocho páginas, se encuentra el "Glosario", cuya primera entrada es la palabra "Wayuu: Tribu indígena localizada en la península de La Guajira Colombo-Venezolana" (10), con lo cual se nota que el texto se dirige a un público lector arijuna. De ahí se incluye una pequeña sección titulada "Lo que dice el Estado", compuesta de la imagen reducida de una carta de la Registraduría Nacional, dirigida a la Doctora Estercilia Simanca Pushaina, la cual consta que

en la actualidad no hay ninguna Ley, Decreto, Resolución o Acto Administrativo, el cual indique que debe consignarse en la cédula de ciudadanía la fecha 31 de diciembre en la parte de nacido tratándose de indígenas wayus que no manejan el idioma oficial de nuestro país. (10)

La página siguiente abarca una foto de la autora con su biografía profesional, que señala que es abogada en ejercicio de la Universidad Simón Bolívar de Barranquilla, así como una lista de sus reconocimientos y tres fotos de su abuela en el Resguardo Caicemapa. La contraportada contiene una imagen ampliada de su abuela y la leyenda explica que: "Mamá Victoria, 107 años de inocencia, al igual que muchos wayuus de su época, nació un 31 de diciembre y manifiesta no saber firmar" (12). Con letra más grande y en vertical aparece el enlace del blog de la autora.

En lo que se refiere al blog de Simanca Pushaina, Luis Alfonso Barragán (2016) hace hincapié acertadamente en que su cuento se convierte en un "producto transmediático":

\begin{abstract}
la autora maneja un blog en el que se informa sobre los procesos legales generados como consecuencia del cuento, además de producirse un documental, en el que se pasa de 'la ficción narrativa' al 'registro histórico'. Todo un complejo performático que no acaba con 'la palabra fijada en el papel' (o en el espacio virtual del blog), sino que permanece en movimiento, pues se convierte en acto político, social, comunal: un acto estético que deviene 'transformación concreta del mundo"”. (348)
\end{abstract}

Efectivamente, en una entrada del blog de 2014, la autora afirmó que a partir de ese momento la Registraduría Nacional permitiría la creación o modificación del registro civil para que el documento incluyese el nombre de la comunidad, esto es, la etnia o pueblo indígena, y también que la escritura del nombre de la persona correspondiese con la fonética, lo cual establecería su derecho a la identidad. Al referirse al papel de su cuento en este proceso, Simanca Pushaina (2014) menciona 
también la película documental dirigida por Priscilla Padilla, Nacimos el 31 de diciembre (2009), y sugiere que "más que un cuento corto ha sido una novela que se reescribió durante 10 años, con muchas coincidencias y con un final feliz". Cabe añadir aquí que, en un reciente simposio internacional de escritores indígenas, celebrado en febrero de 2020 en San Diego, California, Estados Unidos, Simanca Pushaina inició su presentación con la lectura de un fragmento del cuento "Manifiesta no saber firmar", con lo cual se sigue reafirmando el acto político y performático del texto literario.

Ahora bien, Lindsay Perwak (2016) contrasta la portada de la edición ilustrada de "Manifiesta no saber firmar" — de cuya creación estuvo a cargo Simanca Pushaina- con la de su libro anterior, El encierro de una pequeña doncella (2003), de cuya diagramación y preparación se encargó totalmente la editorial. Según Perwak, la portada y el prólogo de El encierro cumplen varias funciones que "operan externamente al texto en el ámbito del paratexto: Primero, declara el género (literatura infantil); segundo, define el público (niños); y finalmente clasifica el contenido temático (fantasía)" (44). Perwak utiliza el concepto de paratexto de Genette para explicar la manera en que los elementos que acompañan el texto mismo, tales como, por ejemplo, el nombre del autor, el título, el prefacio, las ilustraciones, sirven para determinar la manera en que el texto se entiende y se presenta a los lectores. Al criticar tanto la infantilización como la deshumanización en las representaciones de los indígenas a lo largo de la historia colonial, Perwak argumenta que tanto Simanca Pushaina como Vicenta Siosi Pino, otra escritora wayuu, no "rechazan la categorización de sus obras como libros infantiles", sino más bien la aceptan para después invertir el "tropo colonial del indígena infantilizado" mediante otros recursos (35). Al respecto, en una entrevista personal, Simanca Pushaina asevera que sus cuentos "[n]o deberían ser clasificados como infantiles [de] verdad, pero si eso es lo que cree el público lector yo los dejo. Considero que la literatura no tiene jurisdicción ni edad" (Perwak, 2016: 44-45).

En ese sentido, la autora rechaza cualquier encasillamiento de su quehacer literario, ya sea como literatura infantil o literatura indígena, y también como literatura de Abya Yala 6 . En el breve ensayo "Pulowi de Uuchimüin"7, Simanca Pushaina (2015) expresa lo siguiente:

\begin{abstract}
Yo soy la india, la aborigen, la mestiza con origen, soy wayuu. Mi literatura es otra cosa, mi literatura es latinoamericana. [...] Siento que me desvié a tiempo de ese camino llamado Abya Yala, porque cuando los escucho hablar de pureza, de lengua madre, de escribientes y hablantes, no sólo siento que se aíslan, sino que también me llevan con ellos, cuando yo he concebido que mi literatura es para el mundo, no sólo para los wayuu. (321)
\end{abstract}

Simanca Pushaina no habla wayuunaiki y escribe sus textos en español, pero sí tiene la esperanza de que lleguen a formar parte de la tradición oral wayuu, que sus textos se wayunicen (2015: 462): "Se trata de revertir el proceso, ir de lo escrito a lo oral" (2015: 321). En relación con esto, hay que recordar que Coleima, la narradora-

\footnotetext{
${ }^{6}$ Emilio del Valle Escalante (2013) señala que en idioma kuna tule de San Blas, Panamá, Abya Yala significa "tierra en plena madurez", y para muchos se entiende como un "posicionamiento político y como un lugar de enunciación”" - citando aquí a Armando Muyolema - propio y diferenciado de América Latina (11).

${ }^{7}$ En su blog, Simanca Pushaina define "Pulowi" como "encanto femenino" (mito wayuu) y "Uuchimüin" como "hacia el sur".
} 
protagonista de "Manifiesta no saber firmar", es analfabeta. El texto se inscribe precisamente en los intersticios y las relaciones entre mundos - pero también en las brechas intra-mundiales - y así se problematizan las oposiciones o progresiones entre la oralidad y la escritura, así como las categorizaciones y tipologías literarias.

En "Manifiesta no saber firmar" la cuestión de los nombres es fundamental: no sólo se trata de la burla y falta de respeto hacia cada individuo por parte de los funcionarios. Los clanes wayuu son matrilineales y "cada clan está asociado a un animal totémico, es decir que las familias tienen un origen mitológico" (Pushaina, Villa y Villa, 2016: 247). Hay una compleja relacionalidad entre los seres humanos y seres otros-que-humanos que abarca el nombre del clan. Cuando el funcionario le cambia el nombre al individuo, entonces, toda esta relacionalidad se descarta como un exceso — usando la noción de De la Cadena (2015) — una diferencia radical más allá del límite de lo que existe en ese mundo (276). La protagonista del cuento ha logrado mantener su nombre intacto al sacar la cédula: es Coleima, del clan Pushaina. Sin embargo, a lo largo del relato se revelan otros nombres diferentes que se le han impuesto. Coleima descubre que en su partida de bautismo se llama Faride Abuchaibe. El sacerdote de la iglesia le explica que el día de su bautismo, cuando ella tenía unos cinco años, su padrino había bautizado a unos cien "chinitos" y a todos les pusieron Faride y Eduardo Abuchaibe. "Ahora entiendo", señala la narradora, "porque todos me dicen la turca" (8). Sus primos que vivían de sirvientes en la ciudad, en cambio, le llamaban "Pocahontas", como los "indios de los cuentos" que escuchaban de noche antes de dormir en las casas de cemento (8).

No es de extrañar que la noción de entre mundos aparezca de diferentes maneras en la crítica sobre la obra de Simanca Pushaina. Por ejemplo, refiriéndose a "El encierro de la pequeña doncella", María Mercedes Ortiz Rodríguez (2016) propone que la autora "establece un diálogo con la tradición oral wayuu y busca preservarla a través de la escritura" (60). Perwak (2016), a su vez, concluye su estudio sobre Simanca Pushaina y Siosi Pino afirmando que su "posición única como mujeres mestizas no limita el acceso a los dos universos —el dominante y el indígena- sino el contrario: les brinda paso a múltiples puertas de posibilidad", y luego menciona "ese anhelado ambiente intercultural en el cual es posible realizarse como indígena e individuo moderno al mismo tiempo" (93). Sin embargo, lo que queremos matizar aquí son los acercamientos que ponen en tela de juicio las concepciones ontoepistémicas dualistas. En relación con esta idea, Duchesne Winter señala que

El acto de expresar la experiencia indígena en la literatura convencional, en el escenario de las letras llamadas occidentales, no se reduce a un paso hacia la presunta modernidad o la "civilización", sino más que nada es una estrategia afirmativa de una manera autónoma y diferente de vivir. (2015: 15)

Partiendo de distintos conceptos que pueden sugerir formaciones binarias, tales como doble consciencia, nepantla y pensamiento fronterizo, entre otros, Gloria Chacón (2018), a su vez, plantea la noción mesoamericana de kab'awil, una doble mirada, pero como una cosmoléctica-en lugar de dialéctica-que facilita la transgresión de las oposiciones binarias dominantes que suelen informar debates sobre identidades indígenas contemporáneas: moderno-tradicional, individualcolectivo y religioso-secular (21). El "braconaje" identitario, concepto propuesto por Simon Harel, también tiene semejanzas con estas nociones; se plantea como 
"una táctica para desestabilizar la hegemonía universalizante del pensamiento occidental" al posicionarse en la diferencia colonial para criticarla, tal como señala Nicolas Beauclair (2018: 80) en su análisis de la poesía de escritores indígenas. En suma, no se trata de tender puentes entre los extremos, sino más bien de deshacer la ontología dualista hegemónica y así abrir un espacio para la traducción ontoepistémica, un proceso en el cual surgen inevitablemente desacuerdos y tensiones.

\section{Palabrero}

El palabrero, o pütchipü'ü, en lengua wayuunaiki, es una figura central en el pueblo wayuu que "encarna una autoridad tradicional" (Pushaina, Villa y Villa, 2016: 256). El palabrero desempeña el papel de mediador en los procesos de la resolución de conflictos y la negociación de acuerdos, "ya sean graves casos de sangre, arreglos matrimoniales o el manejo de pequeñas querellas" (Guerra Curvelo, 2002: 127). Su recurso principal, tal como indica su nombre, es su don de la palabra. En wayuunaiki, el término pütchi significa palabra y pứú se refiere "a las extremidades inferiores que simbolizan el andar"; así que el pütchipüü, tal como indica Polo Figueroa (2017) es "la persona que lleva la palabra; el andar con la palabra" (46). Guerra Curvelo señala que el palabrero "se asocia en la tradición oral a los pájaros por su despliegue retórico, similar al canto de las aves, despliegue con el que busca lograr la conciliación de las disputas intraétnicas" (127). Como autoridades morales de la comunidad, los palabreros se encargan de entablar conversaciones reconciliatorias entre ofensores y ofendidos con el fin de lograr un acuerdo de reparación y compensación por medios pacíficos; tienen una función imprescindible puesto que, al ejercer su oficio de manera eficaz, pueden evitar que los agredidos recurran a la venganza o bien que el pleito se convierta en una guerra de clanes o familias (Pushaina, Villa y Villa, 2016: 257). La Junta Mayor de Palabreros, reconocida a nivel nacional e internacional, es la entidad responsable de salvaguardar el sistema normativo wayuu, un sistema de justicia basado en lazos de solidaridad y conceptos colectivos de reparación y reconciliación (Polo Figueroa, 2017).

La novela Palabrero, de Philip Potdevin, se inspira en esta figura central del pueblo wayuu. Esta obra forma parte del corpus literario del escritor caleño, el cual, además de obras de poesía, dramaturgia y cuento, incluye seis novelas. Por la primera, Metatrón, Potdevin fue galardonado con el Premio Nacional de Novela Colcultura en 1994. Su quinta novela, Palabrero, publicada en 2016, narra la historia de Edelmiro Epiayú Epiayú, un abogado wayuu que llega a ser uno de los líderes principales de la lucha por salvar el río Ranchería de la empresa minera que quiere desviarlo para poder explotar un yacimiento de millones de toneladas de carbón que se halla debajo del lecho del río. Es una novela de doble formación en que la preparación del protagonista como abogado se va compaginando con su transformación en palabrero, al seguir el linaje de su tío Fulvio, quien muere atropellado por el tren carbonífero. Las vicisitudes relacionadas con esta formación constituyen el conflicto principal de la historia a medida que el protagonista va desarrollando una doble mirada para transitar los espacios entre mundos.

La novela está estructurada en 12 capítulos más un epílogo y la primera mitad del texto se dedica a la formación del protagonista. En el segundo capítulo, Epiayú, narrador intradiegético, va relatando anécdotas de su experiencia universitaria estudiando Derecho en Riohacha; la llegada en los años 1980 de la mina -El Cerrejón, la mina a cielo abierto a la que se alude, pero nunca se nombra en la obra- 
y las costumbres y características de los wayuu. Tras la muerte de su tío Fulvio, Epiayú tiene un sueño en el que aparece un yoluja, "el espíritu de un wayuu muerto" (48), lo cual desencadena la acción de la historia: al joven abogado se le ocurre que él tiene que ser la persona que impida el proyecto de la mina de desviar el río Ranchería. Para salvar el río, y también para descifrar el enigma del sueño, debe viajar a la laguna de Chirigua, "arriba en la distante Sierra Nevada de Umunkumu - no de Santa Marta, como la bautizaron los que llegaron a estas costas hace quinientos años y comenzaron por cambiar el nombre a cada lugar" (57). El tercer capítulo consiste en dicho viaje donde acaba pasando medio año con el mamu Eleuterio Quijada, y aprende de La Línea Negra, una demarcación de treinta y nueve puntos geográficos precisos, que circunda el territorio sagrado, "el centro del mundo; el lugar donde la Tierra palpita para salvarse de los excesos de las depredaciones de los hermanos menores" (78). Al final, Epiayú se une con el agua de la laguna y se convierte en uno de los hermanos mayores. Tras la preparación que recibe del mamu, en el cuarto capítulo Epiayú recibe una formación práctica y su tarjeta profesional trabajando con el abogado valduparense Dagoberto Enríquez, hombre de vastos conocimientos legales y proclive a propinar latinajos. Es en el quinto capítulo, al volver a la ranchería por el motivo de la muerte de su madre, cuando nombran a Epiayú palabrero y le entregan el bastón de su tío.

En este breve resumen de la primera mitad de la novela, se vislumbran unas cuantas instancias de traducción entre mundos que el narrador intradiegético va haciendo; de ahí, tras el atentado contra Epiayú, se vuelve más explícita dicha traducción. Tal como relatará el protagonista posteriormente, mientras sigue sedado e inconsciente en una unidad de cuidados intensivos del hospital, "navegué por el firmamento de La Wajira” (197), camino a Jepira, el destino final donde descansan las almas de los wayuu. En este estado - como espíritu o alma en pena- el protagonista se encuentra con su tío Fulvio, quien le comparte el relato entero de Juan Jacinto, figura histórica que fue líder de la insurrección wayuu contra las autoridades coloniales que empezó en 1762 y duró unos siete años. Resulta que Epiayú tiene el mismo rostro que Jacinto. Más adelante, en un largo capítulo, se narra en tercera persona la historia de la insurrección de este personaje histórico. En este desdoblamiento entre las dos figuras, se vislumbra un mecanismo de la colonialidad de la historia, tal como la describe De la Cadena (2015):

Enraizada en las restricciones epistémicas de la razón (o razón-capacidad), la evidencia legitima el poder de la historia moderna - en su encarnación académica, legal y cotidiana - para discriminar entre lo real y lo irreal. Este poder de la historia sobrevivió la crítica postcolonial: por consiguiente, la entidad social (o acontecimiento) que no proporcione evidencia razonable es irreal. $(147)^{8}$

En este sentido, el recorrido de Epiayú por el camino de Jepira, esto es, su estado temporal como alma en pena - lo cual se podría ver como un "exceso" de la diferencia radical— queda legitimado como "real", precisamente, por la reencarnación de la figura histórica de Jacinto en Epiayú.

\footnotetext{
8 "Rooted in the epistemic strictures of reason (or reason-ability), evidence legitimizes the power of modern history - in its academic, legal, and everyday incarnation - to discriminate between the real and the unreal. This power of history survived the postcolonial critique: accordingly, the social entity (or event) which does not provide reasonable evidence is unreal" (Traducción mía).
} 
En el cuento "Jamü" de Estercilia Simanca Pushaina (2017), también se narra la historia de un alma que anda sin descansar "en un viaje sin fin" (59). El narrador intradiegético relata la historia de su vida y su primera muerte: "Mi nombre es Jamü Epinayu Pushaina, aquí estoy esperando que hagan mi segundo velorio. Mientras tanto, pastoreo en Jepira las almas de los niños muertos" (59). Los wayuu tienen la costumbre de exhumar los restos del difunto a los cinco años o más de muerto para celebrar un ritual que culmina con un segundo entierro de los huesos (Pushaina, Villa y Villa, 2016: 258). Jamü se murió a los siete años y lleva 43 lluvias esperando su segundo velorio, que no ha recibido porque su madre no sabe dónde está enterrado; llegó al hospital sin registro y al fallecer lo enterraron el mismo día con siete niños wayuu más. El protagonista se murió de inanición, en parte, porque su madre no pudo acceder a los recursos proporcionados por el estado: "Mamá nunca tuvo cédula, de esas que dicen 'Manifiesta no saber firmar', debe ser porque no nació el 31 de diciembre, por eso nunca le dieron de esas bolsas, siempre hizo la fila pero regresaba a casa sin la Bienestarina" (61). El vocablo "jamü" en wayuunaiki significa "hambre". En este sentido, el protagonista se puede ver como una sinécdoque de todos los niños wayuu desnutridos y como tal simboliza el abandono del estado en general. A diferencia del encuentro de Epiayú y su tío Fulvio camino de Jepira en Palabrero, en este cuento de Simanca Pushaina el mundo ficticio, constituido por Jepira y los espacios recorridos por un alma, permanece como un exceso de la diferencia radical precisamente porque la narración de Jamü no se cede a otra voz narrativa que sirviese para legitimarla o asentarla ontológicamente en un determinado mundo empírico.

$\mathrm{Al}$ esbozar un panorama de la literatura indigenista, producida principalmente por escritores no indígenas, Chacón (2018) señala algunas tendencias comunes: la conceptualización de los indígenas como víctimas y como una población explotada que carece de conciencia de clase; el uso de descripciones con estereotipos denigrantes; la apropiación de lo indígena como parte de proyectos de formación nacional, entre otras (128-131). La teórica señala que los escritores latinoamericanos, tradicionalmente, explotaban las literaturas orales indígenas como materias primas para su propia producción literaria (129). La superación de estas tendencias predominantes del indigenismo, así como la manera en que la mirada etnográfica de la antropología - y la historia, la geografía y otras disciplinas y campos de estudio occidentales- ha desempeñado un papel significativo en la categorización y jerarquización de la humanidad dentro de la colonialidad del conocimiento, ${ }^{9}$ presentan retos fundamentales en la traducción onto-epistémica. Además de la representación textual de lo indígena y los modos discursivos utilizados, la posicionalidad e intencionalidad de los escritores y hablantes tanto intra como extratextuales cobra suma importancia.

Toda la historia que va narrando Epiayú a lo largo de Palabrero queda enmarcada por el texto escrito por un intermediario, el abogado español, un aliado suyo en la lucha por salvar el río, quien ha venido a Colombia a visitarlo en el hospital tras el segundo atentado contra su vida. El español, cuyo nombre nunca se revela y quien se podría ver como el autor, Potdevin, desdoblado intratextualmente - los dos arijunas funciona como transcriptor-editor, con lo cual el libro asume la forma de un testimonio ficcionalizado. Si bien el testimonio surgió en Latinoamérica en los años

${ }^{9}$ Véase el libro magistral de Linda Tuhiwai Smith (2012), Decolonizing Methodologies: Research and Indigenous Peoples. 
60 como un nuevo género narrativo estrechamente relacionado con los movimientos de liberación nacional y generado en el radicalismo cultural de aquella coyuntura histórica, alcanzó su pleno apogeo con la publicación del relato de Rigoberta Menchú, lo cual contribuyó a la transformación de Menchú en una figura de renombre internacional en $1992 .{ }^{10}$ El testimonio es un género amorfo que se resiste a la categorización, pero en términos generales se trata de una narrativa auténtica sobre una situación urgente —explotación, genocidio, opresión- relatada por un individuo que cuenta su propia experiencia como parte del grupo oprimido. Beverley (2004) hace hincapié en que la fuerza dominante del testimonio es la intencionalidad del narrador, del sujeto subalterno, aunque el texto está mediatizado por la del editor (32) y se plantea como una forma narrativa no ficticia. Con respecto al papel del transcriptor-editor, Chacón (2018) reconoce que la autoridad que adquirió este género en la academia benefició las literaturas indígenas contemporáneas, pero critica la fijación de la misma en esta práctica mediada que también ha eclipsado hasta cierto punto a escritores indígenas (47).

La estructura testimonial puede proporcionar un medio de agencia para voces anteriormente silenciadas, pero al mismo tiempo, paradójicamente, privilegia la escritura por encima de la oralidad — un colaborador intelectual transforma la oralidad del testigo subalterno en texto escrito. Sin embargo, en Palabrero se procura subvertir esta linealidad y así poner en duda el estado ontológico del texto y su autoría. En la última página del relato, el español indica que Rita, la prima y la última pareja de Epiayú, le ha pedido que se encargue de escribir la historia de éste en el caso de que no se recupere y no pueda contársela. Acto seguido, el narrador concluye remitiéndose a la siguiente frase: "¿Es posible robarse un río? Sí, un río" (291). Esta frase, la última "escrita” por el narrador español, también es la primera frase "hablada" por Epiayú al principio de la novela, con lo cual el relato permanece suspendido en una circularidad narratológica entre la oralidad y la escritura.

Hay que señalar asimismo otro nivel narrativo oral que surge en el texto: se van intercalando relatos narrados por Fulvio, el tío del protagonista, lo cual se podría interpretar como una representación de la transmisión oral de conocimientos. La voz de Fulvio se oye en los ocho fragmentos en letra cursiva que abarcan historias con algunas de las enseñanzas de los wayuu acerca del linaje de los palabreros, los animales totémicos, las Pulowi, "aberturas en la tierra que tragan a los animales o a los seres humanos y los guardan en sus entrañas" (83), los yoluja, espíritus de los wayuu muertos, y Jepira, la tierra de los yoluja, que se halla en el Cabo de la Vela, entre otras. Suena la voz de Fulvio, pero es por medio de la de su sobrino, quien va recordando estas historias escuchadas en su niñez:

El pájaro Utta fue el primer palabrero que existió entre los wayuu. Fue quien clasificó a toda nuestra gente en clanes y luego nos dio las normas para convivir en armonía. Por eso boy dia Utta ostenta en su pecho los collares blancos que recibió como premio por su enjundiosa labor. Tiene, escuchen todos, dos características — dijo el tío Fulvio a los carajitos de la ranchería para acaparar nuestro interés - Utta posee el mejor sentido del bumor entre los wayuu además de otra virtud: la clarividencia. (45; itálicas originales)

Relacionado con dos impulsos clave del testimonio - por un lado, la denuncia urgente de una situación de opresión, y por el otro, el acercamiento al grupo

${ }^{10}$ Véanse los siguientes estudios sobre el testimonio: Arias (2001), Beverley (2004) y Gugelberger (1996). 
oprimido- predomina en Palabrero una óptica documental que se mueve entre las dos vertientes de la doble formación del protagonista, su devenir como palabrero wayuu y como abogado. Aquí la noción de óptica documental se refiere a un modo discursivo caracterizado por una pretendida claridad expositiva con aparentes fines informativos o didácticos o bien articulado para proporcionar elementos probatorios en el caso de una denuncia. La primera vertiente consiste en un afán etnográfico de catalogar los elementos culturales de La Wajira, la tierra de los wayuu. Además de las historias de Fulvio ya mencionadas, se intercalan descripciones a lo largo del texto, como, por ejemplo, los siguientes: "Por eso nuestra medicina es natural y conocemos las posibilidades curativas de las plantas, sus usos y aplicaciones, como el coralillo para las convulsiones epilépticas o la batatilla morada para los dolores reumáticos" (15); o bien en otra parte de la narrativa, "unos cactus candelabros de los que mi madre extraía la savia para combatir la bronquitis que llega con las épocas de lluvia o para expulsar el veneno del escorpión” (41). Incluso, a veces se presentan las recetas de los remedios:

[...] vertió en una olleta un poco de agua, con hojas de aceituno, ají cimarrón, balsamira y sábila, mientras que en otra colocó, además de agua, una planta que llamó 'quitadolor', que parecía arrancada de un arbusto de varas largas de las cuales brotaba, de cada una, un ramillete de hojas con flores. Echó dos palitos quebrados y los puso a hervir, junto a la otra cocción. (53)

El uso de este tipo de descripción no se limita a los elementos wayuu. Al llegar a Valledupar en su viaje a la Sierra Nevada en busca del mamu Kumikurwa, uno de los llamados "hermanos mayores" que había sido maestro de su tío Fulvio, Epiayú describe la "indumentaria propia" de los habitantes de la Sierra:

Trajes inconfundibles: siempre blancos, manta, pantalón y faja, así como gorro de algodón y fique en forma de cono truncado, que después aprendí [que] se llama tutusoma y lo usan apretado a la cabeza para dejar asomar las melenas que llegan a los hombros; las mochilas en dos tonos invariables, crudo y marrón, tan diferentes a las cromáticas explosiones de las wayuu [...]. (64)

Más adelante, ahora en busca del mamu Eleuterio Quijada, el protagonista observa a un grupo de hombres kankuamo que llevan poporos durante el viaje en campero hacia el pueblo Atánquez, y uno le explica la costumbre del poporeo:

Nosotros le decimos hayo. Es lo que masticamos junto a la cal de las conchas marinas que recogemos en las playas del Caribe. La guardamos en el poporo para luego frotar el exterior y lograr esta textura blanca, que al remojar de saliva y la savia del hayo, nos permite comunicarnos con la naturaleza. (68)

La novela incluye este tipo de pasajes o fragmentos explicativos sobre otros temas y elementos culturales de los habitantes de la región, tales como los tejidos, la música vallenata, fenómenos lingüísticos, creencias, costumbres y rituales, entre otros. Lo que se destaca aquí es el tono didáctico que cobran estas descripciones dentro de un marco etnográfico general.

La segunda vertiente de la óptica documental que rige la novela consiste en la denuncia de la opresión del pueblo wayuu y los demás habitantes de la zona por parte de la empresa minera que cuenta con el apoyo del estado. El proyecto de la 
desviación del río Ranchería y los efectos nocivos que produciría se ponen de primer plano temático en la historia, pero los distintos aspectos de la destrucción causada por El Cerrejón desde su establecimiento en La Guajira en los años 80 se van enumerando en el texto: la expropiación de tierras, el desplazamiento forzado y violento, la profanación de los cementerios, la contaminación del agua, los daños ambientales y de los cultivos, los efectos perjudiciales del polvillo de carbón como la silicosis y otras enfermedades, la extinción de las fuentes de agua, y la muerte de ganado y de personas atropelladas por el tren que lleva el carbón a Puerto Bolívar, entre otros. La óptica documental de la novela combina descripciones visuales con entrevistas o conversaciones con los habitantes de la zona. En el quinto capítulo, por ejemplo, un líder cívico lleva a Epiayú de excursión por los alrededores de la mina para que pueda presenciar directamente las distintas áreas de la mina - los tajos, el botadero y las llamadas "zonas rehabilitadas" — y también hablar con los líderes de las comunidades aledañas a la mina, las más damnificadas, incluyendo el resguardo Provincial y el de Cerro Hatonuevo. En Palabrero las acciones nefastas del (neo)extractivismo y los megaproyectos se enmarcan en un contexto más amplio de opresión sistémica e histórica de los pueblos indígenas, afrodescendientes y campesinos. Además, la destrucción ambiental provocada por la mina se presenta como cómplice del cambio climático a nivel planetario.

Tal como se mencionó anteriormente, la muerte de Fulvio, atropellado por el tren carbonífero, desencadena la acción principal de la diégesis de Palabrero y también emblematiza la opresión del pueblo wayuu por El Cerrejón. En el cuento "Daño emergente, lucro cesante" de Simanca Pushaina (2017), escrito en 2008, Rukarria Epinayú relata en primera persona cómo el tren atropelló a su burro. La protagonista usaba su burro, Mushaisa, para llevar carbón de leña al mercado de las pulgas, pero hace dos días el tren no pitó el silbato que solía pitar y ella juzgó mal el tiempo para cruzar. Rocha Vivas (2019) asevera que la "voz testimonial revela una crítica impotente ante la violencia extractora de la empresa multinacional El Cerrejón" (280). Rukarria nunca recibe una indemnización por la pérdida de su burro porque la empresa argumenta que había un letrero grande por donde ocurrió el accidente que advertía del peligro del tren en wayuunaiki, lo cual se revela al final del cuento con un cambio de voz narrativa: "NNOJO PAAPÜIN PIKII SÜNAIN OUKTA SULU'U SÜPUNA TÜRENKAT'. Que significa: 'NO ENTREGUES TU CABEZA A LA MUERTE, POR EL TREN'. Pero Rukarria Epinayú no fue a la escuela. Rukarria Epinayú 'Manifiesta no saber firmar"' (Simanca Pushaina, 2017: 67). Rocha Vivas (2019) señala que estos avisos en wayuunaiki se pueden considerar una burla por parte de la empresa puesto que un porcentaje mínimo de la población sabe leer y escribir wayuunaiki (285). ${ }^{11}$ Lo que queremos resaltar aquí es la serie de paralelismos que abarca el cuento: el burro lleva el carbón (de leña) al mercado del pueblo y el tren lleva el carbón de la mina al norte destinado a la exportación internacional; se yuxtapone una rutina cotidiana wayuu con el flujo del mercado globalizado. Además, lo semántico linda con lo ontológico: el vocablo mushaisa, el nombre del burro, significa carbón en wayuunaiki. El tren siempre vuelve a "buscar

\footnotetext{
${ }^{11}$ Rocha Vivas (2019) considera la manera en que el burro reacciona al tren moviendo su cabeza en desaprobación como una "visión de cabeza" del analfabetismo (281): "las visiones de cabeza corresponden a un tipo particular de producciones ideosimbólicas que tienden o aspiran a subvertir y exponer las miradas/lecturas convencionales, estereotipadas, dominantes o hegemónicas sobre los pueblos indígenas [...y] suelen enfatizar diferentes desencantos con la modernidad, así como apropiaciones de esta mediante imágenes de contraste e inversión" (14).
} 
más carbón arañando las entrañas de Mma — la tierra—, la que guarda la sangre de nuestros partos y el ombligo de los recién nacidos" (Simanca Pushaina, 2017: 66). En otras palabras, el burro es el carbón, el sustento de la vida diaria, y el carbón extraído de la tierra es el pueblo wayuu.

Las dos vertientes de la óptica documental que se vienen examinando en Palabrero convergen en el proyecto totalizante que constituye la propuesta estética de Potdevin y culmina con la lucha en contra de la desviación del río Ranchería. Siguiendo la doble formación de Epiayú como palabrero y abogado, se combina la autoridad de la ley de origen indígena - "esa antigua norma, oral y justa, que nos ha regido, no solo a los wayuu, sino a muchos de los pueblos aborígenes de América desde tiempos inmemoriales" (15) — con todo un despliegue de acciones y mecanismos legales que se implementan en oposición a la empresa y al estado. Por un lado, en el texto se hace hincapié en el derecho a la rebelión y se alude a la constitución norteamericana, la cual proclama que "cuando quiera que una forma de gobierno se haga destructora de estos principios, el pueblo tiene el derecho a reformarla o abolirla e instituir un nuevo gobierno" (113), así como a la Declaración Universal de Derechos Humanos, que afirma el "supremo recurso de la rebelión contra la tiranía y la opresión" (114).

Por otro lado, la estrategia específica que lanzan Epiayú y su equipo consiste en dos frentes de trabajo dentro del marco de la ley: un frente internacional en el que recurren a los derechos ratificados en el Convenio 169 de la Organización Internacional de Trabajo sobre pueblos indígenas y tribales (1989) y en la Declaración de las Naciones Unidas sobre el respeto a las comunidades indígenas. Cuentan con el apoyo de fundaciones, documentalistas, activistas e inversionistas a nivel internacional para hundir la reputación de la empresa. En el segundo frente, acuden a la Constitución del 91 y al sistema judicial de Colombia y presentan "quince acciones de tutela, tres acciones populares, dos acciones sociales, dos acciones de cumplimiento", así como la solicitud de revocación de las licencias y los títulos mineros (279). Tal como se nota en los pocos ejemplos proporcionados aquí, la narrativa abarca todo un catálogo de recursos dirigidos a la defensa del río.

En relación con el derecho a la rebelión, aparecen referencias en Palabrero a obras de distintos contextos y épocas como, por ejemplo, Antígona, Fuente Ovejuna y Guillermo Tell, así como Cien años de soledad y el caso histórico de la insurrección de Juan Jacinto que ya se ha mencionado. Sin embargo, en lo que se refiere al presente estudio, se destaca la intertextualidad que incluye la narrativa vinculada a la acción jurídica, política y activista. El protagonista de la novela de Potdevin (2016) inicia su narración de la siguiente manera: "Edelmiro. Edelmiro Epiayú. Edelmiro Epiayú Epiayú. 'Nacido un 31 de diciembre', dice la cédula de ciudadanía. 'Manifiesta no saber firmar', dice también" (19). De ahí el narrador explica que la Registraduría Nacional del Estado Civil expidió documentos de identidad a miles de wayuu "con nombres oprobiosos e información falsa" (19). Este es el primer caso específico de opresión con el cual Epiayú decide enfrentarse como abogado y, con el tiempo, logra una victoria puesto que la Registraduría se ve obligada a rectificar estas vejaciones. Así aparecen intertextualmente la obra literaria y los esfuerzos activistas de Simanca Pushaina — así como la película documental de Padilla - en la novela de Potdevin. Se debe señalar asimismo que el conflicto principal de la obra, la defensa del río Ranchería, también ocurrió en una encrucijada de recursos literarios 
y acción política: en 2012 la escritora wayuu Vicenta Siosi Pino escribió una carta abierta al presidente de la República en defensa del río, la cual se publicó en el periódico El Espectador y fue clave para detener temporalmente el desvío del río. ${ }^{12}$ Esta intertextualidad patente en la novela de Potdevin, no sólo en lo que se refiere a textos escritos sino también de cara a textos orales y otros elementos wayuu, pone de relieve cuestiones de autoría y funcionalidad, sobre todo, cuando un escritor arijuna escribe acerca de un pueblo indígena.

La presentación de cuestiones de identidad de género en Palabrero merece más atención. En su estudio de escritoras indígenas mesoamericanas, Chacón (2018) señala que por medio de la noción de kab'awil estas escritoras mantienen una mirada crítica hacia prácticas sexistas que se aceptan por ser consideradas parte de la tradición (17): "La doble mirada posibilita una crítica de proyectos asimilacionistas, historias del estado-nación, el sexismo dentro de comunidades indígenas y partidos políticos progresivos" (20). ${ }^{13}$ En Palabrero, hay un énfasis en la hombría del protagonista, sobre todo, frente a la figura histórica del insurgente Juan Jacinto. Epiayú tiene relaciones íntimas consecutivamente con cinco mujeres diferentes, las cuales corresponden a sendas etapas de su formación, una por capítulo: Iliana "era menudita, blanquísima, casi traslúcida, catirita de ojos verdes" (31); Manuela era una joven kankuamo (90); Diana, "menuda, oscura como la panela (118); y Yurany era "una mulata preciosa, insinuante" (192). Las relaciones sexuales con las mujeres se describen a veces en términos de uniones telúricas y/o cósmicas. Las características más destacadas de Rita, la prima y la quinta pareja de Epiayú, aparte de su belleza juvenil, incluyen la manera en que se aferra a las costumbres wayuu y expresa lealtad a su primo amante: "Industriosa, consagrada, creativa, en esa época permanecía la mayor parte del tiempo al frente del telar — cuando no en la cocina haciendo hayacas o bollos o cocadas [...]" (22). En conjunto, las relaciones que tiene Epiayú con estas mujeres se puede interpretar como una simbólica unificación fisonómica, multiracial y multiétnica de la región (o la nación). De ahí se podría indagar más a fondo cuáles son los distintos papeles y funciones de los personajes en relación con la construcción de género en la novela, y cómo rompen con las prácticas y tendencias señaladas por Chacón para reflejar la complejidad del tema en las comunidades wayuu, o bien, por el contrario, hasta qué punto refuerzan dichas prácticas en parte, tal vez, debido a un afán etnográfico de captar costumbres y tradiciones dentro de un proyecto totalizante.

La obra cuentística de Simanca Pushaina proporciona un contraste importante en materia de género. Al referirse a sus "cuentos cerreros — rebeldes y contestatarios", Rocha Vivas (2012) asevera que la autora "se viene constituyendo en una voz de conciencia crítica que desde lo femenino refleja aspectos complejos, y por siglos ocultos, sobre las relaciones de género en la dinámica de las prácticas tradicionales" (195). Ortiz Rodríguez (2016) señala a su vez, en su estudio sobre "El encierro de la pequeña doncella", un cuento sobre el ritual del encierro de una joven wayuu tras su primera menstruación, que Simanca Pushaina establece una negociación entre costumbres tradicionales y el mundo arijuna sin caer en una lógica dualista (62). En el cuento “Bultito llorón ¡Cara de indio!", la protagonista, cuyo nombre no se revela,

${ }^{12}$ Rocha Vivas (2019) reproduce y analiza detenidamente la carta de Siosi Pino y señala los recursos literarios que emplea la autora (286).

13 "The double gaze allows a critique of assimilationist projects, nation-state history, sexism within indigenous communities, and progressive political parties". (Traducción mía.) 
narra en primera persona una gran parte de su vida desde anécdotas de su propia niñez hasta que su hijo ya es mayor de edad. Lo que se destaca es cómo la conciencia crítica de la autora se integra en su propuesta estética mediante el uso de un lenguaje poético y la construcción narratológica de la obra. El relato se inicia con el uso de la segunda persona verbal: "No quiero que me pegues por negarte mis besos, mis besos son de verano [...]. Tu boca es la de un abuelo, tu boca pantanosa quiere mis besos de verano" (Simanca Pushaina, 2017: 39). De ahí la narración pasa a la primera persona y se expresa una imagen que se repite más adelante: "Abrí los ojos y vi las estrellas a través de las rendijas del techo nuevo de yotojoro" (39). ${ }^{14}$ La sangre constituye un leitmotiv principal del cuento: la sangre de los golpes que le da su marido; su sangre de doncella; la sangre que su bebé le chupa; y la sangre que ella derramó en el parto y que su madre vino a cobrar. Con sutileza narrativa este cuento se entreteje con los demás relatos de la colección Por los valles de arena dorada mediante las historias, los personajes, los espacios- para crear un complejo entramado de mundos interconectados, un mundo de mundos.

La novela de Potdevin (2016) abarca una visión utópica — tal como reconoce el autor en el epílogo - ya que al final no sólo se logra parar el proyecto de desviar el río sino que también la empresa anuncia que "ha decidido suspender toda actividad de extracción minera en el país" (287). Debido al esfuerzo colectivo y las acciones realizadas, esta lucha se transforma en un plebiscito nacional y el pueblo colombiano da una señal de solidaridad con las comunidades indígenas y el medio ambiente. El segundo atentado contra Epiayú en la plaza principal de Riohacha durante una "gran fiesta nacional" constituye un momento culminante de traducción onto-epistémica que apunta a la integración nacional: "La palabra había triunfado", la palabra del abogado-palabrero logra derrotar la multinacional extractivista; Epiayú alcanza a Fulvio de camino a Jepira y le dice que lo espere; y mientras yace el nuevo héroe nacional en el quirófano, estalla una revuelta en la ciudad (288), lo cual recordará al lector el bogotazo de 1948. Se puede plantear, por una parte, que la (re)creación de este tipo de imaginario utópico a través de la literatura y la producción cultural es imprescindible y, en efecto, puede contribuir a que se haga realidad. Por otro lado, en este desenlace se refleja la asimilación de la resistencia wayuu en el estado nación mediante un proyecto estético que linda con una especie de indigenismo multicultural de la pluralidad, lo cual no se puede reconciliar con múltiples proyectos indígenas de autonomía social, cultural y política.

En una entrevista, Potdevin, quien vivió "casi cinco años en La Wajira (la tierra de los wayuu)", asevera que la novela es un grito literario "para que el wayuu sea escuchado, dignificado y restablecido en su autonomía, en sus valores, en su derecho" (Chica García, 2016). El autor recalca su compromiso con el pueblo wayuu al incluir en el colofón de la novela lo siguiente:

Este libro se terminó de editar el dos de noviembre de dos mil dieciséis, cuando en La Guajira empiezan a caer los responsables de la desnutrición de los niños indígenas y los mayores problemas sociales de este departamento. En medio del plan Bolsillos de Cristal, una gran operación contra la corrupción, comienzan las capturas de los funcionarios que se han robado los recursos de la educación,

${ }^{14}$ En el glosario al final del cuento se indica que "yotojoro" es la "madera del cardón guajiro" (Simanca Pushaina, 2017: 51). 
acueductos, salud, alimentación y atención a la primera infancia, y obras civiles.

(Potdevin, 2016: 296)

De ahí, hay señalar que el plan de resistencia indígena que se desarrolla detalladamente en la novela comparte algunos aspectos clave con casos reales de otros contextos colombianos como, por ejemplo, el proceso relacional que llevaron a cabo los witoto en conjunto con diez grupos indígenas más de la zona de Leticia. Herrera Arango (2017) explica que este colectivo logró conectar la ley de origen indígena con los derechos humanos universales con el fin de hacer frente al estado y conseguir el reconocimiento de los derechos de indígenas desplazados a base de la diferencia cultural (129): "A diferencia de nociones occidentales de derechos humanos, la ley de origen no considera la etnicidad, la ciudadanía y el universalismo necesariamente como mutuamente excluyentes" (130)..$^{15}$ Esta premisa fundamental atraviesa tanto Palabrero como la obra de Simanca Pushaina. ${ }^{16}$

\section{Conclusiones}

Tal como señala De la Cadena (2015), el concepto de conexiones parciales es importante políticamente ya que posibilita

aseveraciones acerca de condiciones indígenas y no indígenas más allá de las taxonomías estatales que, basadas en la práctica evolucionaria y/o multicultural de la pluralidad (es decir, la idea de que la alternativa a uno son muchos), exigen la pureza de una unidad o bien rechazan su existencia (33). ${ }^{17}$

Se trata del reto de negociar los conflictos entre, por un lado, las tendencias relativamente recientes, por parte de los estados, de adoptar discursos multiculturales regidos por una lógica neoliberal, y por el otro, las posibilidades de lo pluriversal, la política ontológica y proyectos autónomos que transciendan el estado nación. Al diseñar sus proyectos literarios en torno a la convergencia de la búsqueda de la justicia por el pueblo wayuu, la estética narrativa y las conexiones parciales entre mundos, tanto Simanca Pushaina como Potdevin realizan una especie de traducción onto-epistémica. En esta breve reflexión se han analizado algunas de las tensiones que surgen en el proceso de visibilizar los desacuerdos ontológicos que se manifiestan en la determinación de lo que es real y la relacionalidad entre seres humanos y seres-otros-que-humanos. La exploración de la posicionalidad de los escritores en relación con los distintos mundos — sin recurrir a oposiciones binarias limitantes - posibilita el análisis de matices clave en las intersecciones de literatura y activismo. Estos textos literarios se inscriben en situaciones que son simultáneamente históricas, respecto a la opresión y resistencia del pueblo wayuu, y urgentes, a la luz de la cifra de asesinatos — que ha ido en aumento desde el acuerdo de paz de 2016 — de líderes indígenas y afrodescendientes

\footnotetext{
15 "In contrast with Western notions of human rights, the law of origin does not necessarily consider ethnicity, citizenship, and universalism to be mutually exclusive". (Traducción mía)

${ }_{16}$ En el mismo sentido, pero específicamente en el contexto de La Guajira, se nota, por ejemplo, la formación del Movimiento Indígena Nación Wayuu, constituida en 2016. Esta ONG articula conexiones fundamentales entre el principio de sumak kawsay, los derechos humanos y colectivos, así como servicios de acompañamiento y asesorías jurídicas. (Nación Wayuu, n.d.)

17 "I use the concept of partial connections as an analytical tool that is also political. It allows assertions of indigenous and nonindigenous conditions outside of state taxonomies that, based on the evolutionary and/or multicultural practice of plurality (that is, the idea that the alternative to one is many), demand the purity of a unit or deny existence". (Traducción mía)
} 
entre otros activistas, líderes sociales y defensores de los derechos humanos y del medio ambiente, frecuentemente en relación con megaproyectos extractivistas.

\section{BIBLIOGRAFÍA}

Arias, A., (Ed.) (2001). The Rigoberta Menchú Controversy. Minneapolis: University of Minnesota Press.

Barragán, L. A. (2016). Palabra de los bordes que transita a través: la oralitura como posible apertura político-cultural. Catedral Tomada. Revista de Crítica Literaria Latinoamericana 4(7), 339-361.

Beauclair, N. (2018). Ontologías poéticas diferenciadas en la literatura amerindia: "Braconaje" y decolonialidad. Visitas al Patio (12), 75-95. https:// doi.org/10.32997/2027-0585-vol.0-num.12-2018-2103

Beverley, J. (2004). Testimonio: On the Politics of Truth. Minneapolis: University of Minnesota Press.

Chacón, G. (2018). Indigenous Cosmolectics: Kab'awil and the Making of Maya and Zapotec Literatures. Chapel Hill, NC: The University of North Carolina Press.

Chica García, A. (2016, diciembre 8). "La novela es un grito literario para que el wayuu sea escuchado": Philip Potdevin. El Heraldo. https://www.elheraldo.co/entretenimiento/la-novela-es-un-grito-literario-paraque-el-wayuu-sea-escuchado-philip-potdevin

De la Cadena, M. (2015). Earth Beings: Ecologies of Practice Across Andean Worlds. Durham, NC: Duke University Press.

Duchesne Winter, J. (Ed.). (2015). Hermosos invisibles que nos protegen. Antología wayuu. Pittsburgh: Instituto Internacional de Literatura Iberoamericana.

Escobar, A. (2016). Autonomía y diseño: la realización de lo comunal (C. Gnecco, Trans.). Popayán: Editorial Universidad del Cauca.

Escobar, A. (2013). Una minga para el postdesarrollo: lugar, medio ambiente y movimientos sociales en las transformaciones globales. Bogotá: Ediciones desde abajo.

Gómez-Barris, M. (2017). The Extractive Zone: Social Ecologies and Decolonial Perspectives. Durham: Duke University Press.

Guerra Curvelo, W. (2002). La disputa y la palabra. La ley en la sociedad wayúu. Bogotá, D.C.: Ministerio de Cultura.

Gugelberger, G., (Ed.) (1996). The Real Thing: Testimonial Discourse and Latin America. Durham, N.C.: Duke UP.

Herrera Arango, A. D. (2017). Safeguarding the Witoto: How indigenous law may challenge the universality of human rights. En A. Fanta Castro, A. Herrero-Olaizola, y C. Rutter-Jensen, (Eds.), Territoris of Conflict: Traversing Colombia through Cultural Studies (pp. 121-134). Rochester, NY: University of Rochester Press.

Nación Wayuu (n.d.). ONG INDÍGENA DE DERECHOS HUMANOS. http://nacionwayuuong.com

Ortiz Rodríguez, M. M. (2016). "Hasta los días se convirtieron": rituales de paso, matrimonio por compra y derechos de las mujeres en la narrativa de las escritoras wayuu Vicenta María Siosi Pino y Estercilia Simanca Pushaina. En G. Castellanos Llanos, (Comp.), Rebelión contra el olvido: mujeres escriben sobre escritos de mujeres (pp. 4763). Cali: Programa Editorial Universidad del Valle.

Padilla, P. (Dir.) (2011). Nacimos el 31 de diciembre. Documental. 
Perwak, L. (2016). Gritos en el desierto: denuncia y resistencia en las obras de las escritoras wayun Estercilia Simanca Pushaina y Vicenta María Siosi Pino. Dissertation. Portland State University. Dissertations and Theses. Paper 3001.

Polo Figueroa, N. (2017). La palabra en la cultura wayúu. Cuadernos de Lingüistica Hispánica, (30), 43-54.

Pushaina, L. E., Villa, E. y Villa, W. (2016). Referencias cosmogónicas y prácticas del buen vivir según el pensamiento de los wayú de Manaure (La Guajira, Colombia). Tabula Rasa 24, 243-26.

Quijano, A. (2000). Coloniality of Power, Eurocentrism, and Latin America. Nepantla 1(3), 533-577.

Rocha Vivas, M. (2019). Mingas de la palabra: textualidades oralitegráficas y visiones de cabeza en las oralituras y literaturas indígenas contemporáneas ( $2^{\mathrm{a}}$ edición). Bogotá: Universidad de los Andes, Ediciones Uniandes; Editorial Pontificia Universidad Javeriana.

Rocha Vivas, M. (2017). Estercilia Simanca Pushaina: un venado en el zapato. En E. Simanca Pushaina, Por los valles de arena dorada (pp. 9-16). Bogotá: Loqueleo.

Rocha Vivas, M. (2012). Palabras mayores, palabras vivas: tradiciones mítico-literarias y escritores indigenas en Colombia. Bogotá: Taurus.

Rocha Vivas, M. (2010). El sol babea jugo de piña: antología de las literaturas indígenas del Atlántico, el Pacífico y la Serranía del Perijá. Bogotá: Ministerio de Cultura.

Simanca Pushaina, E. (2017). Por los valles de arena dorada. Bogotá: Loqueleo.

Simanca Pushaina, E. (2015). Pulowi de Uuchimüin (2013). En J. Duchesne Winter (Ed.), Hermosos invisibles que nos protegen. Antología waynu (pp. 319-321). Pittsburgh: Instituto Internacional de Literatura Iberoamericana.

Simanca Pushaina, E. (2014, noviembre 8). La identidad étnica, el objetivo final. "Manifiesta no saber firmar" Nacido: 31 de diciembre. http:/ / manifiestanosaberfirmar.blogspot.com

Simanca Pushaina, E. (2008). Manifiesta no saber firmar. Nacido: 31 de diciembre, Guajira: edición de la autora.

Smith, L. T. (2012). Decoloniring Methodologies: Research and Indigenous Peoples (2a edición). New York: Zed Books.

Valle Escalante, E. del. (2013). Teorizando las literaturas indígenas contemporáneas: introducción. A Contracorriente 10(3), 1-20. 